\title{
Toxic Effects of Prolonged High-dose Dapsone Self-medication
}

\author{
S. G. BROW NE, M.D., F.R.G.P., F.R.G.s., D.T.M. \\ Leprosy Service Research Unit, Uzuakoli, Eastern Nigeria
}

Early reports of the toxic effects of dapsone in the high doses then given refer mainly to acute haemolytic anaemia and various forms of dermatitis. Although dapsone is currently given for mycetoma and dermatitis herpetiformis in doses higher than those now generally advocated for leprosy, toxic phenomena attributable to these high doses are not common in patients under treatment for these conditions.

Two patients have been seen in Eastern Nigeria in whom prolonged self-medication with excessive doses of dapsone for suspected leprosy led to changes in the skin, damage to the kidneys, and to mental disturbances which were probably secondary to the resulting uraemia.

\section{CASE REPORTS}

A man of about 30, and weighing I25 lbs. $(56 \cdot 8 \mathrm{~kg}$.) was brought by his brother to the Oji River Leprosy Settlement with the story that he had taken as treatment for leprosy (which he himself had diagnosed) four roo mg. tablets of dapsone every weekday for two years. Acting under misguided lay advice, he had taken these heroic quantities in a bold and determined effort 'to get rid of his leprosy quickly'. He had stopped this treatment four months previously. Careful questioning of the brother produced confirmatory evidence that the tablets were indeed dapsone, and that $400 \mathrm{mg}$. had been regularly taken as stated.

On examination, no evidence of active leprosy could be seen in skin or nerves and no $M$. leprae were found in smears from the skin or nasal mucosa, but some hypopigmented areas were present that were typical of healed minor tuberculoid lesions.

The patient was grossly uraemic; his tongue was dry and furred, his breath foul. He was lethargic and mentally confused. Cerebration was very slow, and he understood and responded to questions with great difficulty and retardation. His speech was slurring and indistinct. The face was suffused and oedematous, the eyes being almost closed.

The skin over the entire body was thick and hard, feeling like a tense and tough leather drum-head. It was so bound to the deeper tissues that it could not be plucked up in folds. Over the dorsa of the hands and feet, it was much thicker than elsewhere, and darker, having the appearance and the feel of scorched velvet, dry and hard and finely papular. The lips were fissured and much thickened.

Neither the patient nor his brother associated the gradually developing toxic phenomena with the drug. They attended the Diagnostic Clinic with the object of ascertaining if the patient was still suffering from active leprosy.

There is nothing in the patient's previous medical history to suggest that the impaired kidney function antedated the beginning of dapsone treatment.

The blood showed a slight degree of anaemia.

The urine boiled solid with albumin, and contained numerous cellular casts and erythrocytes.

The patient was seen again four weeks later. Cerebration was rather less slow, but the other signs and symptoms showed no improvement, and the urinary findings were unchanged.

Within three months, a patient presented himself at Uzuakoli with a similar history and with similar, though less severe, toxic manifestations. In this case, however, it was not possible to obtain independent confirmation concerning the dose of dapsone taken (which was probably $400 \mathrm{mg}$.), the frequency (probably three or four times weekly) or the total length of treatment. 


\section{DIS C USSION}

The nephrotoxicity of the sulphones was recognized from early tests on laboratory animals. (The use of diaminodiphenyl sulphoxide was considered inadvisable by Browne and Davey (I962) because of its toxic action on the kidney.) When given in therapeutic doses, however, even for prolonged periods, dapsone itself is rarely the cause of demonstrable kidney damage.

The diverse manifestations of cutaneous sensitivity to dapsone are well known, but the peculiar hyperkeratosis here reported, however, appears to be unrelated to drug sensitivity, and seems rather the result of prolonged toxic action on the epidermis. Apart from the generalized oedema, the changes in the skin may reasonably be attributed to the weekly ingestion over two years of $2.4 \mathrm{gm}$. of dapsone.

The mental condition was similar to that frequently observed in uraemia, and does not indicate a specific action of dapsone on the cerebral tissues.

S UMMAR Y

A case is reported in which an adult man had treated himself with a daily dose of $400 \mathrm{mg}$. of dapsone six days a week for two years, suffering from severe damage to kidneys in consequence. The retarded cerebration noted was probably uraemic in origin. The skin of the dorsa of hands and feet was hyperkeratotic, dry and hyperpigmented.

\section{A GKNOWLEDGEMENTS}

My thanks are due to Dr W. Felton Ross, the then Area Superintendent of the Oji River Leprosy Control Area, for showing me the first patient, and to Dr S. O. Egwuatu, Chief Medical Officer, Ministry of Health, Eastern Nigeria, for permission to publish this article.

REFERENCE

BRowne, s. G. and DAVEy, T. F. (I 962 ). Leprosy Rev., 32, I 94. 